\title{
Aportación documental sobre la minería peruana: Cajatambo, 1584-1596
}

\author{
M. ${ }^{a}$ Isabel Aragón Sánchez \\ Universidad de Sevilla
}

El objetivo prioritario de este trabajo es presentar la transcripción, acompañada de estudio introductorio, de una documentación hallada en el Archivo General de Indias que, por ser poco conocida, puede interesar a los estudiosos de la minería bajoperuana del siglo XVI. Basándonos en dicha documentación, hemos intentado abordar algunos condicionantes de la problemática minera de Cajatambo: partimos del descubrimiento en 1584 de las minas argentíferas de Chingos, para desembocar en el estudio de los diferentes aspectos pertenecientes a la creación de un centro minero que, si bien se mantuvo durante toda la época colonial española, por motivos diversos no logró alcanzar las expectativas que en un principio despertó. Las minas recién descubiertas hicieron pensar en otro Potosí pero, pocos años después, los mineros se hallaban arruinados.

Palabras clave: Minería, Bajo Perú, Cajatambo, XVI, decadencia.

The chief aim of this work is to offer a transcription and introductory study of a littleknown document encountered in the Archivo General de Indias, Seville, which may be of interest to scholars of lower-Peruvian mining in the sixteenth century. On the basis of this documentation, analysis is made of some of the factors affecting mining in Cajatambo. The article begins with the discovery of the silver mines of Chingos in 1584. It goes on to review different aspects relating to the establishment of a mining centre which, though remaining active throughout the whole of the Spanish colonial period, for various reasons failed to fulfil the expectations held of it. At their discovery the mines raised hopes of a new Potosí, but just a few years later, miners at the centre were ruined.

KeYwords: Mining, Lower Perú, Cajatambo, XVIth-century, decline.

\section{Introducción}

Durante los siglos XVI y XVII Cajatambo ${ }^{1}$ fue un corregimiento constituido por cinco repartimientos de indios, perteneciendo, ya en el siglo XVIII, a la Intendencia de Tarma. Tras la Independencia, Cajatambo se

1 El origen del nombre de Cajatambo parece ser que se encuentra en la unión de dos palabras quechuas: " casha", que significa espina, y "tampu”, que significa posada. Inicialmente surgió la palabra "Cashatampu" (Caxatambo) y el hecho de que en esta región existiera en la época prehispánica un tambo resguardado por altos y frondosos espinales, parece que apoya esta teoría sobre el origen de su nombre. 
incluyó en diferentes departamentos peruanos (Huaylas, Tarma, Ancash), hasta que en 1917 pasó a formar parte de la provincia de Lima. ${ }^{2}$

Situada a unos $170 \mathrm{~km}$. de Lima y a una altitud de $3.350 \mathrm{~m}$. sobre el nivel del mar, la actual Cajatambo se encuentra en la zona nordeste de la capital peruana, extendiéndose en su mayor parte por la sierra andina. Su clima es, en general, frío y saludable y posee un nivel aceptable de lluvias, sobre todo en las zonas altas y medias.

Debido a sus características geográficas y propiedades del terreno, Cajatambo combina hoy la actividad agrícola (papas, ocas, ollucos, maíz, trigo, habas, cebada) con la ganadera (llamas, alpacas y especialmente ovejas) y minera (en la actualidad, la producción de plata se ha sustituido por la de molibdeno). ${ }^{3}$ Ríos como el Rapay, Copa, Izco, Cajatambo, Gorgor, Cochamarca, Pachangará y Oyón, aunque, en general, de régimen irregular, han ofrecido sus aguas desde antiguo para el riego de los cultivos y como fuerza motriz para ingenios y molinos. ${ }^{4}$ Por todo ello, este lugar, emplazado en la sierra cisandina, ha constituido un hábitat más que aceptable para el establecimiento humano. Ya en 1533, el soldado-cronista Miguel de Estete escribía sobre Cajatambo:

“...Este es un pueblo grande y está en un valle hondo y es de muchos ganados; e hay por todo el camino desde Chinchi hasta él que serán cuatro leguas, mucha cantidad de corrales e ovejeros..."

Efectivamente, el ganado llevado por los españoles era ya abundante en estas tierras y no es de extrañar que, a finales del siglo XVIII, los obrajes significaran una ganancia importante para los habitantes de Cajatambo, siendo la producción de lana su principal comercio. ${ }^{5}$ En cuanto a sus minerales, muy pronto, tras la conquista del Perú, los nuevos colonos descubrirían allí minas de mercurio - como fue el caso del poeta y minero lusitano Henrique Garcés ${ }^{6}$ - y minas de plata que mantuvieron las esperanzas de

2 Sobre la geografía de Cajatambo, ver: Alcedo y Herrera, Antonio de: Diccionario GeográficoHistórico de las Indias Occidentales o América, 5 vols. Licencia de Imprenta de Benito Cano, Madrid, 1. ${ }^{\mathrm{a}}$ ed. 1786-1789, T. I. Luza, Manuel: "Apuntes Monográficos de la Provincia de Cajatambo", Boletín de la Sociedad Geográfica de Lima, T. LXXI, trimestres 3. ${ }^{\circ}$ y 4..$^{\circ}$ (Lima, 1954), págs. 26-38.

3 El molibdeno es un mineral empleado en aleaciones férricas.

4 No obstante, el retraso en la ejecución de obras de canalización y la falta de una política eficaz de irrigación han impedido el desarrollo de una agricultura más variada y de mayor producción.

5 Ver Alcedo y Herrera, Antonio de: Diccionario Geográfico-Histórico ..., T. I.

6 Lohmann Villena, Guillermo: "Enrique Garcés, descubridor del mercurio en el Perú, poeta y arbitrista". Anuario de Estudios Americanos, V (Sevilla, 1948), págs, 439-482. Bermúdez-Gallego, Marta: Ipetrarquismo y aculturación. "La canción al Perú” de Henrique Garcés, Rutgers, University Press, 1989. 
muchos de ellos durante toda la época colonial, haciendo de Cajatambo un centro minero cuyo interés se dilataría en el tiempo, pese a la decadencia del siglo XVI aquí comentada.?

\section{El documento}

Como sabemos, la actividad minera en el Perú colonial no dejó de considerarse una buena forma de probar fortuna para quienes llegaron al nuevo continente con la esperanza de enriquecerse. Desde que en 1545 los españoles registran oficialmente las vetas descubiertas en el cerro de Potosí, ${ }^{8}$ los hallazgos de minas de plata se suceden y proliferan en el virreinato peruano. En la segunda mitad del siglo XVI, con la puesta en marcha del sistema de amalgamación en el Perú, ${ }^{9}$ cualquier descubrimiento minero era suficiente para activar los mecanismos de control sobre la posible riqueza. Y éste fue el objetivo de la administración colonial y de los hombres que buscaban trabajo y enriquecimiento en esas nuevas minas.

El rey era informado lo antes posible de cada nueva "mina rica" de vetas, se hacían los ensayos oficiales con la mayor diligencia y, en caso de ser satisfactorios, se ponía en marcha la construcción del centro minero, que más tarde daría lugar a una villa, situada en sus alrededores. Pero también fue frecuente el descubrimiento de muchos yacimientos cuya riqueza

7 En 1799 Cajatambo tenía en explotación 23 minas de plata. Fisher, John R.: Mineros y minas en el Perú colonial, 1776-1824. Instituto de Estudios Peruanos (IEP), Lima, 1977, pág. 197.

8 Los primeros registros oficiales tuvieron lugar en abril de 1545, pero se cree que los españoles descubrieron la plata del cerro potosino entre 1543-1544. I. M. Ballesteros Gaibrois ("Notas sobre el trabajo minero en los Andes con especial referencia a Potosí (s. XVI y ss.)", VI Congreso Internacional de Minería, Cátedra San Isidoro, León, 1970, vol. I, págs. 532-533), apunta la posibilidad de que Gonzalo Pizarro fuese el descubridor de Potosí apoyándose en las afirmaciones del minero Nicolás de Benino, quien sostenía que Gonzalo explotó un socavón en la parte baja del Cerro.

9 A Enrique Garcés corresponde la aplicación en 1565 del sistema de amalgamación por vez primera en el Perú. En una de sus probanzas, nos dice que efectuó el beneficio - aprendido por él en Nueva España- en la provincia de Huamanga con mineral de plata de las minas de Tunsulla, cercanas a las de mercurio de Huancavelica. Pero sus esfuerzos, así como los de otros mineros que lo aplicaron en la zona, no culminaron en la amplia difusión que se pretendía. Será bajo el mandato del virrey Francisco de Toledo cuando el sistema de amalgamación (inventado y puesto en marcha en 1555 por Bartolomé de Medina en la Nueva España), obtenga un máximo rendimiento en el Perú, gracias a la positiva aplicación que, hacia 1571, realizó Hernández de Velasco con el mineral de Potosí. Ver Sempat Assadourian, C.: “ Base técnica y relaciones de producción en la minería de Potosî”. En: Antonio Lafuente y José Sala Catalá, eds.: Ciencia Colonial en América. Alianza Editorial, Madrid, 1992, págs. 121-142. También Francisco de Toledo. Disposiciones gubernativas para el virreinato del Perú, 1569-1574. Transcripción y edición de M. a J. Sarabia Viejo. Escuela de Estudios Hispanoamericanos, CSIC - Monte de Piedad y Caja de Ahorros de Sevilla, Sevilla, 1986, pág. 77. 
sólo se encontraba en la superficie, como fue el caso de las minas de Nuestra Señora del Rosario, en Cajatambo, descubiertas en el repartimiento de Chingos (partido de Corgón) por Alonso López de Barriales, en 1584.

Estas minas presentaron en los ensayos iniciales tan alta ley de plata, que animaron a muchos mineros a invertir su dinero en la construcción de ingenios, e incluso a endeudarse por medio de préstamos, para llevar a cabo las explotaciones. Sin embargo, algunos años más tarde, concretamente, en 1596, el minero Juan Fernández de Hinestrosa menciona en una Relación breve y sumaria dirigida a Felipe II, las minas de Chingos, como ejemplo de mineral cuya riqueza sólo se encuentra en la superficie, provocando la rápida ruina de los mineros. ${ }^{10}$ Dicha relación nos muestra una visión crítica de la minería de finales del siglo XVI, hecha precisamente "desde adentro", es decir, por un minero coetáneo del período que estudiamos. A través de ella - junto con los informes oficiales que se realizaron para la explotación minera de Cajatambo- se pueden analizar algunos aspectos de la problemática minera andina y considerar este centro minero como característico de una época, de una política y de una sociedad.

Entendemos, además, que los informes oficiales del Archivo General de Indias que presentamos en este trabajo son básicos para el estudio de la minería de Cajatambo en el siglo XVI ${ }^{11}$ ya que, hasta ahora, las investigaciones sobre este lugar del Bajo Perú se han enfocado mayoritariamente desde la temática religiosa que supuso en la época la "extirpación de las idolatrías", ${ }^{12} \mathrm{o}$ desde su interés como camino real prehispánico. ${ }^{13}$

10 Archivo General de Indias (en adelante AGI), Charcas, 134, fol. 13rto. "Relación Breve y Sumaria dirigida a Felipe II por el minero Juan Fernández de Hinestrosa”, 1596.

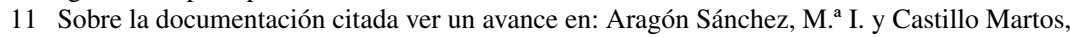
M.: "Datos inéditos del trabajo en las minas de Cajatambo en el siglo XVI". Actas del XI Congreso Internacional de AHILA ( Asociación de Historiadores Latinoamericanistas Europeos), editadas por John R. Fisher, 4 vols. Institute of Latin American Studies, University of Liverpool, Liverpool, 1996, vol. III, págs. 105-113.

12 Aunque hubo una estrecha relación entre la extirpación de las idolatrías y la prospección minera en el virreinato peruano, creemos que existen pocos estudios sobre el tema específicamente minero en la provincia de Cajatambo durante el siglo XVI. Ver Duviols, Pierre: Cultura andina y represión. Procesos y visitas de idolatrías, Cajatambo, siglo XVII. Cusco, Centro de Estudios Rurales Andinos "Bartolomé de la Casas", 1986. García Cabrera, Juan Carlos: Ofensas a Dios, pleitos e injurias. Cajatambo, siglos XVII-XIX. Cusco, Centro de Estudios Rurales Andinos "Fray Bartolomé de las Casas", 1994. Salazar-Soler, Carmen: "Las huacas y el conocimiento científico en el siglo XVI: a propósito del descubrimiento de las minas de Potosí”. En: Saberes y memorias en los Andes, In Memoriam Thierry Saignes. T. Bouysse-Cassagne, ed. Vol. 1. Institute des Hautes Études de 1'Amerique LatineInstitute Francais d'Études Andines, Lima, 1997, págs. 237-257. .

13 "Cajatambo, la ruta de los incas". Versión html del archivo: http://www.gabrielepoli.it/andares/foto26/cajatambo.doc. Con información de los arqueólogos Guido Casaverde, Edwin Rivera Camacho, Joseph Bernabé Romero y José Quinto Palacios. 
El documento aquí comentado era conocido en la época como despacho de armada. El citado escrito, dirigido el 12 de abril de 1585 a Felipe II y enviado por el oidor Alonso Criado de Castilla, constituye un interesante informe sobre el proceso que se seguía en las postrimerías del siglo XVI tras el descubrimiento de una mina. Dicho documento consta de tres partes, que hemos diferenciado como Documento I, Documento II y Documento III.

El I, titulado De la riqueza que muestran los metales de las nuevas minas de Cajatambo y el ensaye que se hizo por azogue, contiene una detallada información sobre el procedimiento que se usaba en la época para conocer la calidad del mineral de plata descubierto. Este proceso, conocido como "ensayes al pormenor", debía realizarse oficialmente en la Casa de Fundición de Lima, delante de un oidor de la Audiencia y de, al menos, dos oficiales reales más. Las pruebas tenían que hacerse bajo la supervisión del maestro azoguero de dicha Casa. ${ }^{14}$

El relato de los pasos seguidos durante los días en que se efectuaron los ensayos al pormenor, en el que se incluyen las cantidades y proporciones de metal argentífero y de mercurio, así como los aspectos técnicos empleados, nos aporta una rica información sobre el sistema de amalgamación (en cuanto a esos ensayos), hasta ahora poco conocida, ya que, por lo general, los especialistas en el tema se remiten al libro de Alonso Barba conocido como El arte de los metales, escrito en 1640, para el análisis de las primeras pruebas de este tipo en el Perú. ${ }^{15}$

El Documento II, titulado: Testimonio de lo que ha valido a S. M. el azogue de las minas de Huancavelica los años 1580-1584, es un informe presentado a Felipe II por el "secretario del rey y de cuentas reales", Blas Hernández, una vez tomadas las cuentas de la Real Hacienda a Garci Martínez de Vela, a la sazón encargado del recaudo de la misma. ${ }^{16}$ Aunque no se refiere al centro minero aquí estudiado y por eso lo excluimos del apéndice, es, sin duda, un documento interesante para el estudio desglosado y pormenorizado tanto de la producción de mercurio de las minas de

14 Aragón Sánchez, M. ${ }^{a}$ I. y Castillo Martos, M.: " Creación de un centro minero en los Andes. Cajatambo 1584-1585”, Casa de la Libertad, Año 4, núm. 8 (Sucre, 2000), págs. 85-92.

15 Alonso Barba, A.: Arte de los metales. Prólogo de Enrique Calvo. Barcelona, Labor DL, 1977.

16 Hemos de advertir un error en la referencia a este documento expresado en el tomo VIII de la Minería Hispana e Iberoamericana, Lima I, sobre Documentos existentes en el Archivo General de Indias, sección Lima. Cátedra de San Isidoro, León, 1974, pág. 245, en el punto 1.271: "Testimonio de lo que ha valido a S. M. el azogue de Huancavelica desde 1580 hasta 1584, noviembre 22...", ya que lo ubica en los folios 509rto. y 510vto. del legajo 273 de la sección Lima del AGI. cuando realmente pertenece a los folios 508 y 509 . Se da la circunstancia de que el folio 510vto. de dicho legajo, así como el 511rto., de los que hablaremos más adelante, contienen una rica información sobre las minas de plata de Cajatambo. 
Huancavelica como de su rentabilidad en el Perú del siglo XVI. El período que abarca permite un seguimiento por quinquenios, ya que parte de 1580 y llega hasta el 22 de noviembre de $1584 .{ }^{17}$

El despacho de armada concluye con el denominado Documento III. Este informe final, contenido en un pliego, aborda un doble tema. Por un lado, Criado de Castilla, como comisario de las cuentas del rey en el Perú y como juez de bienes de difuntos, informa a la Corona del envío de lo recaudado para la Hacienda Real. ${ }^{18}$ Por otro, expresa las expectativas creadas por el descubrimiento de las minas de plata de Cajatambo y la necesidad de mano de obra indígena para trabajarlas. ${ }^{19}$

Este interesante informe aborda la localización de las minas recién descubiertas en ese lugar, la calidad del mineral de plata, las ventajosas características climáticas de la zona, la abundante población indígena y el tema del trabajo compulsivo, para terminar pidiendo el pronunciamiento real sobre la utilización de la mano de obra nativa bajo el sistema de mita en las citadas minas.

\section{De López de Barriales a Fernández de Hinestrosa: auge y decadencia}

Cuando se descubren las nuevas minas de plata de Cajatambo (1584), la máxima autoridad de gobierno estaba representada por la Audiencia de Lima, ya que el recién nombrado virrey, conde del Villar, no llegaría a esa

17 Las minas de mercurio de Huancavelica (descubiertas en 1563) se trabajaron como monopolio real durante todo el período colonial español. En los años que abarca este documento, el contrato para su explotación estaba establecido con el minero Carlos Corzo, mediante el régimen de Compañía. Esta familia de mineros se hallaba al frente de los trabajos de explotación del mercurio, recibiendo de la Corona la mano de obra necesaria mediante el sistema de trabajo compulsivo conocido como mita y, a cambio, debía pagar la quinta parte de lo producido al rey. Ver: Lohmann Villena, G.: Las minas de Huancavelica en los siglos XVI y XVII. Escuela de Estudios Hispanoamericanos, Sevilla, 1949. Vila Vilar, Enriqueta: "Ensayos metalúrgicos en Potosí: Carlos Corzo de Leca y su nuevo método de amalgamación", Europa e Iberoamérica: cinco siglos de intercambios. Actas del IX Congreso de AHILA, Coord. M. ${ }^{a}$ Justina Sarabia Viejo y Otros. 3 Ts. AHILA-Consejería de Cultura y Medio Ambiente (Junta de Andalucía), Sevilla, 1992, T. II, págs. 379-393.

18 Con respecto al tema de la Real Hacienda, sólo comentaremos dos puntos que llaman la atención en este apartado: el primero es que lo recaudado como bienes de difuntos en 1585 (54.868 pesos), según el propio Criado de Castilla, fue la mayor cantidad recogida hasta esa fecha en el Virreinato. Y el segundo punto, la implantación por el mismo oidor de las tres llaves para la caja de la Real Hacienda, que, como informa a la Corona, no existía hasta entonces en el Perú.

19 Curiosamente, encontramos el pliego que contiene este informe cosido al legajo 273 de la sección Lima del Archivo General de Indias, por la parte que debía quedar abierta, hecho que impedía su lectura, y que nos hizo pensar estar delante de un documento con una "virginidad" de más de cuatrocientos años. 
ciudad hasta finales de $1585 .{ }^{20}$ De todas formas, el tribunal primero y el virrey después, intentaron conseguir el máximo rendimiento del mineral de plata encontrado en el repartimiento de Chingos. El oidor Alonso Criado de Castilla, por comisión de la Audiencia, hizo las primeras averiguaciones sobre esas minas, supervisó los ensayos para comprobar la calidad del mineral argentífero y, como ya comentamos, a él correspondió informar al rey de todo lo que se sabía hasta esa fecha (12 de abril de 1585) sobre el nuevo hallazgo. Los primeros ensayos oficiales se llevaron a cabo en plenas fiestas navideñas del año 1584, y se utilizó el sistema de amalgamación, sacándose un $5.59 \%$ de plata pura por quintal, ${ }^{21}$ aunque para estas pruebas se escogieron las mejores muestras del mineral. ${ }^{22}$

La alta ley de plata obtenida superaba en mucho la calidad del mineral que se beneficiaba por aquel entonces en el famoso cerro de Potosí, ubicado en el Alto Perú. Este hecho fue la razón principal para conseguir la autorización real que posibilitaría activar la maquinaria para la creación de un centro minero en Cajatambo. Pero existían otras razones no menos importantes, tanto para los mineros como para las autoridades del Perú, por las que interesaba explotar esas minas.

Para los mineros, iniciar nuevas explotaciones significaba poder acceder a la mano de obra que, bajo el sistema de mita, les permitía entrar en la fórmula de conmutar el trabajo mitayo por capital monetario invertible en otros sectores; es decir, la práctica ya generalizada en el Perú de finales del siglo XVI consistente en cobrar en dinero a la comunidad indígena por los mitayos asignados (rezagos) que, por un motivo u otro, no comparecían a cumplir con su trabajo. ${ }^{23}$ En teoría, con este dinero, los mineros debían contratar a los sustitutos que posibilitaran la buena marcha de las explotaciones y, aunque así se hacía cuando las minas ofrecían una excelente rentabilidad, en el caso de minas no pro-

20 Vargas Ugarte, Rubén: Historia del Perú. Virreinato ( 1551-1600), 3 Ts. s/e., Lima, 19491958, T. I, págs. 339, 343-344.

21 Aragón Sánchez, M. ${ }^{a}$ I. y Castillo Martos, M.: "Datos inéditos ...”, pág. 106. Véase también de ambos autores: "Creación de un centro minero ..."

22 AGI, Lima, 273, fol. 510vto.

23 Ver: Sempat Assadourian, Carlos: "La producción de la mercancía dinero en la formación del mercado interno colonial", en E. Florescano ( compilador): Ensayos sobre el desarrollo económico de México y América Latina (1500-1975 ), Fondo de Cultura Económica, México, 1987, págs. 223-292. Del mismo autor: Minería y espacio económico en los Andes, siglos XVI-XVII. IEP, Lima, 1980. Abecia Baldivieso, Valentín: Mitayos de Potosí, una economía sumergida. Técnicos Editoriales Asociados, DL, Barcelona, 1988. Bakewell, P.: Mineros de la Montaña Roja: El trabajo de los indios en Potosí. Alianza América, Madrid, 1989. 
ductivas esta práctica ofrecía la posibilidad de invertir ese dinero en cualquier tipo de empresas.

Un somero análisis nos revela que el colectivo minero, como tal, aún no tenía una entidad definida en estas fechas. Como apunta Miguel Molina, ${ }^{24}$ los hombres de minas combinaban esta actividad con otras en calidad de comerciantes, hacendados, milicias, cargos públicos, etc. Aunque los mineros mantuvieron una constante como colectivo multi-sectorial durante todo el período colonial, no tuvieron, por lo general, durante el siglo XVI la base económica que, con el devenir del tiempo, les brindaría la explotación minera. Pese a que, ciertamente, el sistema de amalgamación posibilitó la producción a gran escala y lo que Molina llama "el universo minero", ${ }^{25}$ aún nos encontramos lejos de poder considerar la existencia de una élite minera, y por ello, de la imagen del minero rico de épocas posteriores. ${ }^{26}$

Por lo expuesto, y sin descontar las excepciones de algunos mineros poderosos, las expectativas para los hombres de minas en las postrimerías del siglo XVI, tras cada descubrimiento minero, no se ceñían sólo a la riqueza del mineral, sino a la ganancia que podían obtener disponiendo de una mano de obra - la indígena - a la que explotar de múltiples formas e incluso "vender" extraoficialmente. Esto era lo que, de hecho, estaba ocurriendo en Potosí, justo en esos años. Además, el traspaso de indios de mita estaba originando la aparición de sociedades ficticias para poder optar a un número determinado de mitayos, cuyo fin fue, exclusivamente, esa "venta" de indios. Así se manifestaba el minero Luis Capoche en 1585, sobre la compraventa de los indios de mita: "Y el pobre del indio es una moneda con la cual, se halla todo lo que es menester, como oro, plata, y muy mejor". ${ }^{27}$

Con respecto a la figura del descubridor de las minas de Nuestra Señora del Rosario de Cajatambo, Alonso López de Barriales, podemos observar, por un lado, que conocía muy bien el entramado del mundo mine-

24 Molina Martínez, Miguel: "El minero como grupo social”. En América, Hombre y Sociedad: Actas de las Primeras Jornadas de Historiadores Americanistas. (Santa Fe, Granada, 11 al 15 de octubre de 1987). Ed. Diputación Provincial, Granada, 1988, págs. 245-253.

25 Ibidem., pág. 246.

26 En la línea de los mineros multi-sectoriales y ricos destaca, ya en el Potosí del siglo XVII, López de Quiroga. Ver: Bakewell, Peter: Antonio López de Quiroga ( industrial minero del Potosí colonial). Universidad Boliviana "Tomás Frías”, Potosí, 1973.

27 AGI, Charcas, 134. "Relación General de la Villa Imperial de Potosí por Luis Capoche", fol. 81vto. 
ro y las posibilidades que ofrecía, ya que fue dueño de un ingenio de moler metales en la ribera potosina, además de ser propietario de varias minas de plata y oro. ${ }^{28} \mathrm{Y}$, por otro lado, su faceta de funcionario, teniendo en cuenta que, entre 1555 y 1558, había ejercido el oficio de ensayador de Cuzco, que, unos años más tarde, el Licenciado Castro lo había nombrado ensayador de Potosí y que el virrey Toledo le designó tesorero de la Casa de la Moneda y ensayador de la misma, ${ }^{29}$ por lo que conocía bien la calidad de los metales; de hecho, participó como ensayador en las primeras pruebas oficiales que se hicieron en la Casa de Fundición de Lima con el mineral de Cajatambo. Sin embargo, pocos años después de ponerse en marcha la explotación de las minas de Nuestra Señora del Rosario, este soldado, ${ }^{30}$ funcionario y minero, ${ }^{31}$ totalmente arruinado, recurre a la clemencia real para poder subsistir, junto a su familia, en el rico virreinato del Perú. Queremos resaltar su petición, por otra parte usual en la época, de que "se le hiciese merced" de un repartimiento de indios por dos vidas que le rentase cuatro mil pesos ensayados, ${ }^{32}$ con lo que muestra que una importante fuente de riqueza se hallaba en la disponibilidad de mano de obra indígena. El propio oidor Alonso Criado de Castilla sigue esta línea en su informe sobre las minas de Cajatambo. ${ }^{33} \mathrm{~A}$ este punto concreto nos referiremos más adelante al hablar de minería y razón de Estado.

Sin embargo, esta realidad estuvo imbricada con otros factores que incidían directamente en la buena marcha de cualquier centro minero. Un ejemplo de ello lo proporciona el minero Juan Fernández de Hinestrosa, quien en 1596 escribe al rey sobre la ruina de muchos mineros, refiriéndose, entre otros, a los descubridores de las minas de Chingos en Cajatambo, como comentamos al principio de nuestro trabajo. ${ }^{34}$ Para Fernández de Hinestrosa, la causa de este desastre económico radicaba en el desconocimiento de la naturaleza de los minerales y de la influencia de los planetas en los mismos, señalando la existencia de minas cuya riqueza superficial se extinguía en muy poco tiempo:

28 Alonso López de Barriales se dedicó también a la construcción de nuevos ingenios y maquinaria que facilitaran las explotaciones mineras. AGI, Lima, 580, Lib. 9, fol. 51. Real cédula en Madrid, 10 de noviembre de 1588 .

29 Ibidem, fols. 51 y 52.

30 Ibidem. En 1552, Alonso López de Barriales sirvió al rey luchando contra el levantamiento de Sebastián Castilla en Charcas y en 1553 contra la rebelión de Hernández Girón iniciada en Cuzco.

31 Ver: Aragón Sánchez, M. ${ }^{a}$ I. y Castillo Martos, M.: "Datos inéditos...", págs. 109-110.

32 AGI, Lima, 580, Lib. 9, fols. 51y 52.

33 AGI, Lima, 273, fol. 510 vto.

34 AGI, Charcas, 134, fols. 13rto. y 14rto. 
“... y visto los ensayes, y por la grandeza que los mineros informan, les dan muchos indios que piden, los cuales mineros sin atención de lo que ven por los ojos, y sin más consideración, se arrojan a hacer ingenios y a gastar espléndidamente, y en cuanto se han de aprovechar de los metales para sacadles la riqueza que han prometido encima de la tierra, se hallan que los mantos no pasan de una vara de hondo y las vetas ricas que mostraron plata cuajada y estar encajadas dos o tres estados y no más se pierden los metales como ha acontecido en los Chingos y Cajatambo y Vilcabamba y Julcani y Machaca y los Aullagas, que se quedaron los ingenios armados y sin metales, y asî quedan los mineros perdidos y gastados los créditos y tenidos por charlatanes si acaso hicieron gastar a otros sus haciendas, y no consideraron que las minas ricas que cuajan la plata encima de la tierra son minas de cabeza que, hallando disposición de tierra dispuesta a cuajarse la plata según orden de la naturaleza con el ayuda de la influencia de los planetas mayores y menores..."

Evidentemente nos encontramos en un período histórico en el que los conocimientos científicos, tal como podemos considerarlos hoy, no tienen lugar. En el caso de la minería, concretamente, se observa la conjunción de la alquimia, el conocimiento empírico y la astronomía. ${ }^{35}$ Pero también asistimos en este final de siglo a "la fiebre de las invenciones" en el campo de la metalurgia, sobre todo desde que, precisamente en 1585, el mineral que se saca en Potosí comienza a presentar baja ley de plata. A raíz de esto, escribe Juan Núñez Maldonado, alcalde ordinario de la Villa Imperial por este tiempo:

“....Muchas personas han comenzado a hacer muchas experiencias e invenciones en el beneficio de los metales para que se perdiese poco azogue o sacarse más ley del mineral". ${ }^{36}$

Sin embargo, la mayoría de estas invenciones no tuvieron el respaldo de las autoridades para ser llevadas a una práctica generalizada en estos años finales del siglo XVI, porque la misma Corona las frenó. Se producía un choque de intereses entre los mineros y la metrópoli; para los primeros, el ahorro de azogue significaba aumentar sus beneficios pero para la Corona, que ostentaba el monopolio de las minas de Huancavelica, la disminución de ese consumo, por estas fechas, implicaba justamente lo contrario. Un ejemplo de ello lo tenemos en el minero Carlos Corzo, a quien,

35 La necesidad de adecuar una técnica efectiva al mineral cajatambino, llevó en las postrimerías del siglo XVIII, concretamente en 1792 y en la Hacienda de Bellavista, a que el científico Antonio Zacarías Helms experimentara con una máquina para facilitar el molido y beneficio del mineral de plata de la zona.

36 Jiménez de la Espada, Marcos: Relaciones Geográficas de Indias, Perú, Ministerio de Fomento, Madrid, 1881-1897, 4 vols. T. II, apéndice n. ${ }^{\circ} 4$, pág. CXXV. 
por cierto en estos años, el monarca arrendó el asiento de Huancavelica. Carlos Corzo había inventado (junto con su hermano), un nuevo sistema para beneficiar la plata por hierro, reduciendo el consumo de mercurio ${ }^{37} \mathrm{y}$ a ello se dedicó durante más de un año, gastando en su empeño la suma de treinta mil pesos. ${ }^{38}$ Encarcelado por deudas, escribía al virrey para que se le reconociera su invento, concediéndole mano de obra indígena para aplicarlo, pero la respuesta real fue contundente:

"Yo he sido informado que algunas personas han inventado en las minas de Potosí nuevas formas de sacar plata con hierro y escoria de él sin azogue, y que además de no tener sustancia estas invenciones, sólo sirven de impedir el sacar plata y no gastar azogue hasta ver si salen con ello, y que en caso que saliesen, serían en mucho daño y perjuicio de mi hacienda, pues no se puede ofrecer para su beneficio cosa más importante que consumirse cada año de siete a diez mil quintales del dicho azogue y que importan cuatrocientos mil pesos y que así convendría mandar cesar las dichas invenciones....". ${ }^{39}$

Hemos intentado destacar en esta rápida visión de la minería en las postrimerías del siglo XVI algunos de los principales factores que intervenían en lo que a la prosperidad de un centro minero se refiere: calidad y cantidad del mineral, disponibilidad de la mano de obra necesaria, conocimientos técnicos, intereses de la metrópoli o, lo que es lo mismo, razones de Estado. Atendiendo a este último punto, hay que volver al informe sobre las minas de Cajatambo que Criado de Castilla envía al rey, ya que señala en él, por un lado, la importancia de la minería para la conservación del virreinato al referirse a Potosí y a Huancavelica como columnas que sostienen el Perú; y por otro, y con este mismo fin, la necesidad política de conceder indios mitayos a los mineros, puesto que, como sucede en el caso potosino, disponer de indios es motivo suficiente para ejercer de poblado-

37 Eugenio Maffei y Ramón Rua Figueroa nos remiten (Apuntes para una Biblioteca Española de libros, folletos y artículos, impresos y manuscritos relativos al conocimiento y exploración de las

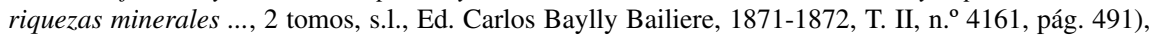
al Manuscrito original en la signatura J. 58, fols. 365 a 372 de la Biblioteca Nacional fechado en Potosí, 9 de marzo de 1588: "Testimonio como no se contradixo por los factores de los azogues el beneficio de los metales con hierro molido". Vila Vilar, E.: "Ensayos metalúrgicos en Potosí ...”, págs. 380-387.

38 AGI, Lima, 273, fol. 169rto. El factor de azogues Carlos Corzo al virrey marqués de Cañete. Potosí, 4 de febrero de 1590.

39 AGI, Lima, 570, libro 15, fols. 69vto. y 70rto. El rey al virrey del Perú. San Lorenzo del Escorial (Madrid), 22 de septiembre de 1590. Hemos de señalar que, a pesar de los impedimentos que puso la Corona para la difusión del invento de Carlos Corzo, muchos mineros potosinos lo utilizaron en sus labores metalúrgicas durante un período de más de 25 años. En: Vila Vilar, E.: "Ensayos metalúrgicos en Potosí ...”, pág. 387. 
res y colonos los españoles, sosteniendo el sistema colonial y generando otros tipos de riquezas y beneficios para el mismo. Con este pensamiento, el oidor expone al rey la importancia de repartir indios a los mineros de Cajatambo, aunque las minas recién descubiertas no prosperasen..$^{40}$

No sería, por cierto, la primera vez que se repartieran indios de minas bajo el sistema de mita en la provincia de Cajatambo; con anterioridad, concretamente en 1577, el virrey Toledo ya había repartido 600 indios $^{41}$ para el cerro de Colquechaca, ${ }^{42}$ cuyo mineral se había presentado con menor ley de plata que el de las minas descubiertas en 1585.

Está comprobado que, en el caso de las minas de Chingos, en Cajatambo, el componente indígena sufrió desde el principio de las explotaciones toda clase de abusos. ${ }^{43}$ Mientras las autoridades esperaban el permiso de la Corona para efectuar los repartimientos oficiales de mitayos, los indios de Cajatambo ${ }^{44}$ fueron forzados a trabajar las minas sin disponer de hospital, el corregidor de la provincia saqueaba la caja de la comunidad indígena y el virrey del Perú informaba sobre ellos al monarca de que sólo trabajarían en las minas si eran forzados, ya que su naturaleza los hacía ociosos e inclinados a vicios. ${ }^{45}$ Desde 1586 se estaban haciendo ya repartimientos de mitayos para las minas de Chingos por parte del virrey Conde del Villar, y en 1589, es el rey quien, al aprobar y mantener vigentes las Ordenanzas de Minas del virrey Toledo, ${ }^{46}$ legitima el trabajo compulsivo de los indios en todas las minas peruanas que, a criterio de la autoridad virreinal, lo requiriesen. ${ }^{47}$

40 AGI, Lima, 273, fol. 510vto.

41 Ibidem.

42 Maffei, E. y Rua Figueroa, R.: Apuntes para una Biblioteca Española, T. II, n. ${ }^{\text {4162, pág. }}$ 491. "Testimonio de la repartición de los indios que se dieron a las minas de Caxatambo". Manuscrito original con signatura J. 58, fols. 418-426vto. de la Biblioteca Nacional. Hay que aclarar que el nombre del cerro de Colquechaca, en Cajatambo, al que se refiere el manuscrito, coincide con el de otro centro minero ubicado en el Departamento de Potosí, en la actual Bolivia.

43 Aragón Sánchez, M. a I. y Castillo Martos, M. : “Datos inéditos ...”, págs. 107-109 y 111. fol. 510vto.

44 La población autóctona de Cajatambo se estimó en 1585 en 17.000 indios. AGI, Lima, 273,

45 AGI, Lima, 32, lib. 3, fol. 27vto. El virrey conde del Villar a Felipe II.

46 Sobre las Ordenanzas del virrey Toledo ver: Francisco de Toledo. Disposiciones gubernativas para el virreinato del Perú. Introducción de G. Lohmann Villena, transcripción y edición de M. ${ }^{a}$ J. Sarabia Viejo. 2 Ts. Sevilla, EEHA, CSIC - Monte de Piedad y Caja de Ahorros de Sevilla, 1986 y 1989.

47 AGI, Patronato Real, 238, n. ${ }^{\circ} 1$, r. 8. 


\section{Apéndice}

\section{[ DOCUMENTO I ]}

\section{Informe enviado por el oidor Alonso Criado de Castilla a Felipe II}

\section{Testimonio de la riqueza que muestran los metales de las nuevas minas de Cajatambo según el ensaye que se hizo por azogue ${ }^{48}$}

/Fol. 504rto./ Muy poderoso señor: Alonso López de Barriales por si y en nombre de sus compañeros dice que ellos descubrieron ciertas minas muy ricas en el cerro de Nuestra Señora del Rosario que es en Chingos, en el repartimiento de Cajatambo y dieron mina a Vuestra Real Persona, y aunque hizo el ensaye del metal, para más satisfacción de que las dichas minas son muy ricas y para seguir y que de ello Vuestra Real Persona será muy servido, trujo dos quintales de metal para que ante uno de vuestros oidores se haga el ensaye del dicho metal y que se entienda la riqueza del.

A vuestra Alteza pido y suplico mande nombrar persona que haga el ensaye del dicho metal y que a ello asista uno de vuestros oidores con vuestros oficiales reales para que se le dé noticia a Vuestra Real Persona del ensaye que se hiciere y sigan, labren y beneficien las dichas minas en lo cual recibiré bien y merced. Alonso López de Barriales.

Decreto: que para el postrero día de Pascua se haga el ensaye en un quintal y éste se entregue a Jerónimo de Yporry, ensayador de esta casa, el cual lo incorpore con el azogue que los oficiales reales le darán y se junten con el señor doctor Castilla cuando se incorpore y desazogue.

Salió proveído lo de suso decretado de acuerdo de justicia en Los Reyes en veinte y dos de diciembre de mil quinientos ochenta y cuatro años.

J. de Montoya

/Fol. 504vto./ En la Ciudad de los Reyes en veinte y nueve días del mes de diciembre fin del año de 1584, el señor doctor Alonso de Castilla

48 AGI, Lima, 273, fols. 504-507. Ciudad de los Reyes, 22 de diciembre de 1584 a 8 de enero de 1585. Rubricado por los escribanos J. Montoya y Juan Ramos de Gauna. Se ha actualizado la transcripción. 
en cumplimiento del decreto de suso estando en la fundición de las casas reales de esta ciudad, por mano de Jerónimo de Yporri, ensayador de esta fundición, hizo pesar un quintal de metal de la mina del cerro de Nuestra Señora del Rosario del repartimiento de Cajatambo contenido en la dicha petición que descubrió Alonso López de Barriales y sus consortes y compañeros, el cual dicho metal molido y cernido se echó en una batea grande y al uso común del beneficio de los metales de plata por azogue echó al dicho quintal salmuera y luego trajo D. Francisco Manrique de Lara, factor y veedor de la Hacienda de S. M. de esta dicha ciudad, en una botija cuarenta y siete libras y dos onzas de azogue y pesada por el dicho Jerónimo de Iporry se echó la dicha cantidad de azogue al dicho metal molido y cernido y se envolvió y repasó tres o cuatro veces dentro de la batea el dicho metal de plata y azogue y hecho este beneficio quedó encerrado en la dicha fundición la batea donde estaba el dicho metal y se llevó las llaves /Fol.505rto./ del aposento, donde quedó encerrado, el dicho señor doctor Castilla y fueron testigos de ello el dicho factor D. Francisco Manrique de Lara; tesorero Antonio Dávalos y el contador Tristán Sánchez y otros muchos que asistieron por la fama de la riqueza del dicho metal y el dicho doctor Castilla lo firmó de su nombre. El doctor Alonso Criado de Castilla. Ante mí, Juan Ramos de Gauna.

En la dicha ciudad de Los Reyes en treinta y un días del mes de diciembre del dicho año, el dicho señor doctor Alonso Criado de Castilla, prosiguiendo en la experiencia y beneficio del dicho metal y por su mandado el dicho Alonso López de Barriales en la forma que se acostumbran semejantes beneficios, dio dos repasos al dicho metal y hecho esto, se quedó encerrado y se llevó la llave el dicho señor oidor. El doctor Alonso Criado de Castilla. Ante mí, Juan Ramos de Gauna.

En la Ciudad de los Reyes en dos días del mes de enero de mil quinientos ochenta y cinco /Fol. 505vto./ años, presente el dicho señor oidor se hizo otra diligencia en el beneficio del dicho metal en la forma que se hizo a los treinta y uno del mes próximo pasado y quedó como está dicho encerrado el dicho metal. El doctor Alonso Criado de Castilla. Ante mí, Juan Ramos de Gauna.

En la dicha Ciudad de los Reyes en tres días del mes de enero de mil y quinientos y ochenta y cinco años, se hizo con el dicho metal otra diligencia como la de suso y se dieron repasos y pareciendo ser el metal de mucha plata y haber menester mucho azogue para incorporar y abarcar la plata, se le echaron otras catorce libras y cuatro onzas de azogue, a lo cual 
se halló en persona el dicho señor doctor Alonso Criado de Castilla. El doctor Alonso Criado de Castilla. Ante mí, Juan Ramos de Gauna.

En la dicha Ciudad de los Reyes en cuatro días del mes de enero de mil y quinientos y ochenta y cinco años, presente /Fol. 506rto./ el señor Castilla, se dio otro repaso al dicho metal y se dejó encerrado como en todas las demás veces desde que empezó la dicha experiencia. El doctor Alonso Criado de Castilla. Ante mi, Juan Ramos de Gauna.

En la Ciudad de los Reyes, en cinco días del mes de enero del dicho año en presencia del señor doctor Castilla y ante mí el dicho secretario, el dicho Alonso López Barriales dio otro repaso del dicho metal y le echó otras nueve libras de azogue, que por todas, son setenta y una libras y después de echado el azogue, dio otros dos repasos, y con esto se dejó encerrado el dicho metal como de suso está referido en la dicha fundición. El doctor Alonso Criado de Castilla. Ante mí, Juan Ramos de Gauna.

En la dicha Ciudad de los Reyes en siete días del dicho mes y año se dio otro repaso al dicho metal presente el dicho doctor Castilla y se dejó cerrado con la llave como se ha hecho en todos los demás beneficios. El doctor Alonso Criado de Castilla. Ante mí, Juan Ramos de Gauna.

/Fol. 506vto./ En la dicha Ciudad de los Reyes en ocho días del mes de enero del dicho año, el dicho Alonso López de Barriales, estando presentes los señores presidente y oidores de esta Real Audiencia, echó el dicho quintal de metal con el azogue que se incorporó en él de la suerte que estaba beneficiado en una tina de agua y con un torno y artificio la empezó a deslamar y lavar desde las diez y media de la mañana que salieron de la Audiencia hasta las doce y otro día siguiente, a la propia hora se prosiguió en lavar el dicho metal y se sacó pella de metal y azogue habiendo sacado todo el azogue que pudo salir por un paño de holanda bien apretado treinta y cuatro libras y media de pella de plata y azogue y veintinueve libras y diez onzas de azogue neto, y hecho una piña, se puso la dicha pella de plata y azogue en un desazogadero y se le dio fuego y bien requemado y desazogado quedó de plata neta once marcos y cinco onzas. El doctor Alonso Criado de Castilla. Ante mí, Juan Ramos de Gauna, Y yo el dicho Juan Ramos de Gauna escribano mayor de gobernación del Perú por Su Majestad, presente fui a lo que de suso de mi se hace mención y por ende hice aquí mi signo. 
[ DOCUMENTO III ${ }^{49}$ ]

\section{Alonso Criado de Castilla al rey}

\section{Sobre el caudal que lleva la armada española, las minas recién descubiertas de Cajatambo y petición de mitayos ${ }^{50}$}

/Fol. 510 rto./ La hacienda de Vuestra Majestad que aquesta armada del Perú lleva a cuya expedición vine a este puerto por Vuestra Real Audiencia, es de novecientos y ochenta y cinco mil doscientos y sesenta y cuatro pesos y un tomín ensayados en las partidas que el testimonio que va con esta refiere.

De lo que a particulares pertenece son dos millones y trescientos y ochenta mil y ochocientos y cincuenta y dos pesos ensayados y doscientos y once mil y seiscientos y cuarenta pesos corrientes que fueron registrados en el registro Real.

De difuntos, en cuyos bienes me ocupó este año ser juez, he recogido la mayor parte que acá se ha visto que monta cincuenta y cuatro mil y ochocientos y sesenta y ocho pesos y de ellos quedan los que pudieron ir conforme a la carta cuenta.

Reduje la caja de esta Real Hacienda a la orden de tres llaves que antes no había para que no anden fuera de ella y se proceda por forma y concierto que Vra. Magd. por sus ordenanzas quiere, y por haber sido comisario ese mismo año de las cuentas de Vra. Real Hacienda, envío con ésta el testimonio de todos los cargos en sumario y de la data y final alcance de ellas con puntualidad precisa para que Vra. Magd. en breve lo sepa.

49 Como hemos indicado en el texto, no se incluye el Documento II porque se refiere a Huancavelica.

50 AGI, Lima, 273, fols. 510-511, desde el Puerto de Lima, 12 de abril de 1585. El oidor Alonso Criado de Castilla a Felipe II. Como ya se ha indicado anteriormente, este documento se había cosido al legajo por la parte que debía quedar abierta, por lo que los folios 510vto. y 511rto. no pudieron ser consultados hasta que advertimos del error al personal facultativo del Archivo General de Indias y éste nos posibilitó la lectura de los mismos. 
/Fol. 510vto./Y por que también del patrimonio real no es menor parte la que de las minas de azogue a Vra. Magd. pertenece, me pareció conveniente certificar a Vra. Magd. que es un millón y cuatrocientas treinta y nueve mil y seiscientos cuatro pesos de plata ensayada de lo procedido de ellas de los años de ochenta hasta veintidós de noviembre de ochenta y cuatro, según las cuentas que con la Real Audiencia yo he tomado, y por este testimonio parece junto con el cual envío a Vra. Magd. otro de vuestra Real Hacienda que estos días se ha mostrado en el descubrimiento de ciertas minas ricas, que a treinta leguas de esta ciudad, en la sierra aparecieron en la provincia de Cajatambo de cuyos metales se vio la prueba por ensaye de azogue, asistiendo yo a todo ello por comisión de Vra. Audiencia, las cuales respondieron con tan próspero exceso, cuanto se ve respecto de lo que en Potosí sucede, a do estiman que por quintal acuda a tres pesos y aquí acudió a mas de once marcos como por los autos se muestra y aunque las piedras en que se hizo esta experiencia se escogieron de las mejores vetas, se ve que en común prometen mucha riqueza porque son en gran cantidad y de mucha apariencia y para más certinidad envía Vra. Real Audiencia a hacer sobre esto toda diligencia. La región do estas minas están, que es de apacible temple, abunda en frutos de trigo, maíz, ganados y otros naturales de esta tierra, es bien poblada de indios, que en distancia y dentro de treinta leguas, tiene más de diecisiete mil contados por los repartimientos. En un tiempo, Vro. visorrey Don Francisco de Toledo aplicó para la labor de otras minas de menos esperanza en aquella provincia seiscientos indios, y por esta Real audiencia no se ha dado licencia que puedan sino es de su voluntad ir a ellas conforme a Vras. Reales cédulas, a cuya causa, porque los indios rehuyen este trabajo no se labran hasta consultar a Vtra. Magd. como lo hace esta audiencia. Gran comodidad será para estas minas no estar muy distantes de las de azogue y en efecto acercarse Potosí a Huancavelica como de esta manera sucedía era de gran interés. Y en esta materia, puesto que la brevedad que este despacho de armada requiere tan poco lugar me deje para escribir a Vra. Magd. en este puerto, la codicia del real servicio hace que diga, aunque en breve, que es el intento que en esta carta llevo, algo de lo sustancial que se ofrece reservando para lo escribir en otra más por extenso, y en suma, los dos ricos cerros de Potosí y Huancavelica que son columnas do estriba este Perú y los manantiales de do nace su riqueza, se sustentan en tener indios que anden en la labor de ellos, porque habiéndolos han metido el día de hoy los españoles que allí entienden en esto, tantas prendas que por no las dejar, aunque los metales 
vengan adelgazándose, al menos no se apartarán de ese entretenimiento por ser gente que no tiene otro oficio ni hacienda, y aunque no ganen nada harán lo mismo con solo andar o como dicen, bullir con el dinero fresco, y en esto viene a parar y resolverse cuanto cerca de esta materia se podía decir en muchos papeles.

Empero /Fol. 511rto./ cuanto a la justificación si estos naturales pueden ser echados al trabajo de estos metales, aunque bien se paguen, no tengo entera resolución conmigo cual deseo para decir a Vra. Magd. lo que siento, esperando a que de más de lo que por derecho soy obligado a saber, venga a estar cierto del hecho que en esto pasa con más experiencia por no engañarme con relación ajena de la gente de esta tierra, do se atreven por costumbre decir muchas veces lo que no sucede, por donde no escribo a Vra. Magd. otras muchas cosas que para adelante, como he prometido me prevengo, más podré con verdad a Vra. Magd. hacer cierto que son estos naturales dignos de la benignidad con que Vra. Magd. los fomenta y favorece para lo cual suplico a Vra. Magd. entre lo demás considere que esta extremada riqueza que rinde a Vra. Magd. esta tierra procede de otro mayor extremo de suma pobreza cual tienen estos indios míseros siervos si se puede decir, por naturaleza, los cuales, si se quitasen de [en] medio cesaría de todo punto la plata como por lo arriba dicho se prueba, no porque ellos la posean, siendo pobres tan verdaderos, sino por ser instrumentos en sacarla de las entrañas de la tierra.

En Potosí han tenido este año buen invierno, que es la sustancia por la molienda de los ingenios para cogerse tan copiosa cosecha como esta armada lleva y no menos adelante se espera, mostrando en esto naturaleza con tan largo tributo, el reconocimiento que siendo Vra. Magd. quien lo recibe será debido mayormente al inmortal nombre de su real grandeza a cuya S. C. R. M. conserve Nuestro Señor largos años continuándolos después con los de su gloria eternos. En el Callao de los Reyes, 12 abril, 1585. S. C. R. Md, humilde y leal criado de Vtra. Magd. que las reales manos beso, Alonso Criado de Castilla. 